\title{
Adaptación intercultural en migrantes retornados: Un estudio en Zacatecas, México
}

\section{Intercultural adaptation in returned migrants: A study in Zacatecas, Mexico}

Dulce María Fernanda Tovar Chávez

Georgina Lozano Razo

Universidad de Guadalajara

\section{Resumen}

La migración es un fenómeno complejo, debido a todas las implicaciones y consecuencias que trae consigo (Serafi y Gimeno 2006), las cuales giran en torno a distintos ámbitos, como pueden ser la búsqueda de empleo, las relaciones sociales, culturales y problemas económicos, entre otros (Centro Internacional de Derechos Humanos de los Migrantes [CIDEHUM], 2011). Por estas razones, los migrantes intentan integrarse de lleno a la cultura dominante, pero conservando su identidad de origen (Casasa, 2008). Lo que los encamina a buscar personas que pertenezcan a su ciudad de procedencia, para lograr mantener su identidad cultural y crear una comunidad trasnacional (Sassone, 2007). Considerando lo anterior, se decidió realizar una investigación que permitiera identificar las principales problemáticas de adaptación intercultural a las que se enfrenta un migrante, así como también los aprendizajes y experiencias adquiridas en ese mismo entorno social. A través de entrevistas a profundidad a cinco migrantes retornados de Estados Unidos al municipio de Fresnillo, Zacatecas, se encontraron como principales dificultades de adaptación el idioma, el hecho de no contar con documentos legales y someterse a una dura explotación laboral.

Palabras clave: migración, cultura, interculturalidad, adaptación e identidad cultural.

Nota del autor

Dulce María Fernanda Tovar Chávez, Universidad de Guadalajara. Av. Juárez No. 976, Colonia Centro, C. P. 44100, Guadalajara, Jalisco, México. Correo electrónico: dulce tovar 95@hotmail.com Apoyo financiero del Programa Delfín-Programa Interinstitucional para el Fortalecimiento de la Investigación y el Posgrado del Pacífico. Georgina Lozano Razo, Universidad de Guadalajara. 


\begin{abstract}
Due to the consequences and possible everyday life implications, such as a job search, social and cultural relationships and economic problems (Centro Internacional de Derechos Humanos de los Migrantes [CIDEHUM], 2011), migration has become a complex phenomenon (Serafi, 2006). Given these implications, migrants attempt to fully integrate to the dominant culture while still keeping their cultural identity (Casasa, 2008). To do so migrants seek people belonging to their city of origin, thus creating a transnational community (Sassone, 2007). The current manuscript used qualitative methods to identify the main problems arising from intercultural adaptations in returned Mexican migrants. Learning and experiences in their social environment were also explored. Five migrants who returned from the United States to their hometown (Fresnillo, Zacatecas, Mexico), were interviewed. Results demonstrate that the main problems faced related to cultural adaptation were language barriers, lack of citizenship paperwork and workplace exploitative practices.
\end{abstract}

Keywords: migration, culture, interculture, adaptation and cultural identity.

Según el Instituto Nacional de Estadística y Geografía (INEGI, 2010), la migración es un cambio de residencia de una persona, temporal o definitivo. A través de este proceso, se busca mejorar la situación socioeconómica, personal y familiar. Por otro lado, la Organización Internacional para las Migraciones (OIM, 2006) señala que la migración es un movimiento poblacional de un territorio a otro, o bien, dentro del mismo país. No obstante, los viajes de negocios, turísticos o de estudios no se consideran migraciones, pues no implican reorganización vital (Micolta, 2005).

De esta manera, cuando una persona abandona su lugar de residencia, se convierte en emigrante, y al momento de establecerse en la nueva ciudad, pasa a ser una persona inmigrante (INEGI, 2010). Según la OIM (2006), la inmigración se refiere al ingreso de una persona a un país con el propósito de establecerse ahí y la emigración es el acto de salir del país con el fin de asentarse en otro. De acuerdo con el INEGI (2010), existen tres tipos de migración: el primer tipo se da cuando una persona solamente se mueve de un municipio a otro. El segundo, cuando la persona se muda de un estado a otro y el último implica el cambio de país de residencia.

Alfonzo (2002) enlista algunas de las causas que determinan la migración: motivos económicos, educacionales, políticos, climáticos y de parentesco. Por otro lado, Gamze, y Kemal (2006), hablan sobre los factores de empuje y atracción que llevan a las personas a migrar, por ejemplo, las represiones políticas, económicas o de violencia son factores de empuje (Ibáñez, 2008), mientras que la oportunidad de bienestar, al trasladarse a lugares donde la recompensa por su trabajo sea mejor que en su país de origen es un factor de atracción (Arango, 2003). La teoría Push-Pull se refiere a la salida del lugar 
de origen y a la atracción en el lugar del destino (Mager, 2014). En otras palabras como lo explica Pérez (2011), "hay factores que 'empujan' a los individuos a salir de su área de origen y hay factores que 'atraen' a esos migrantes a una determinada área de destino" (p. 416). Para ejemplificar de una mejor manera los factores de empuje y atracción, se afirma que la economía es un factor de empuje, ya que la necesidad de mejorar la situación laboral, el salario, a pesar de la sobreexplotación a la que se puedan enfrentar, se convierte en una razón que encamina a la población a tomar la decisión de migrar a otro país. En contraste, el factor de atracción es la necesidad de bienestar, es decir, que de esta manera se podrán mejorar las condiciones de vida (Padro, 2014), como la salud, la vivienda, la educación y la alimentación, que son factores fundamentales para vivir de una manera digna (Villarreal, 2017).

Recordemos que un motivo importante por el que las personas migran es mejorar la calidad de vida del migrante y su familia, paradójicamente, el proceso migratorio tiene efectos que impactan desde el ámbito personal hasta el comunitario, los cuales se ven reflejados en las actitudes y valores de los migrantes (Huesca, Arellanez, Pérez, \& Rodríguez, 2006). Algunas de estas consecuencias son demográficas, económicas y sociales, y estas pueden darse tanto en el país de origen como en el de destino (Consejo Nacional de Población [CONAPO], 2010). La migración se presenta como un componente demográfico importante, pues influye en el crecimiento poblacional y en las tasas de fecundidad y mortalidad de los países que expulsan o reciben migrantes en altas demandas (Rodríguez, Turra, Oliveira, \& Wajnman, 2013).

Los efectos económicos pueden variar; lo que se ha estudiado es que las migraciones pueden servir para terminar con desequilibrios económicos entre países (Alba, \& Besterio, 2001), tal es el ejemplo de las remesas, como lo menciona Aragonés, Salgado y Ríos (2008): “el gobierno mexicano a través del manejo de las remesas no está respondiendo a las exigencias de la población mexicana y sí indirectamente a Estados Unidos que requiere flujos migratorios importantes para continuar con el desarrollo de su economía" (p. 39). Es decir, en este caso las remesas benefician más a la economía estadounidense gracias al trabajo-exportador que no atiende al problema de la pobreza, por lo cual la inmigración de población mexicana, es necesaria para el desarrollo de la economía norteamericana, independientemente de que se trate de una inmigración ilegal o legal (Martín, 2005).

En cuanto a las alteraciones sociales y culturales, Pérez (2007) habla del choque entre el emigrante y el nuevo entorno social, así como la pérdida de redes de apoyo social, lo cual se ve reflejado en la dificultad de adaptarse culturalmente, tema que se abordara más adelante. Rodríguez y colaboradores (2013), mencionan que también los migrantes se enfrenta a problemas como las conductas sexuales de riesgo, la depresión, el abuso del alcohol, pero la drogadicción y el pandillerismo tienen mayor relevancia, debido al alto consumo de sustancias nocivas que se da en el sur y sureste de los Estados Unidos. 


\section{Migración en México}

La movilidad de población entre México y Estados Unidos es un fenómeno que se ha mantenido como una constante en la historia de la relación entre estos países (Canales, 2012). Por más de un siglo, la migración tuvo sus orígenes en la región occidente del país, sin embargo, a finales de los ochenta se comenzó a presentar en el sureste del país (Pérez, 2012). Por otro lado, Durand y Arias (2014) mencionan que la situación migratoria en México, ha sido un tema de total investigación debido al incremento en el número de migrantes de retorno y notable disminución de los flujos de salida. Sin embargo, para el año 2014, más de 11.7 millones de mexicanos residían en los Estados Unidos, población que ha ido en aumento en la última década (Zong, \& Batalova, 2016), de tal manera que, para el 2016, de los 55 millones de hispanos que residían en Estados Unidos, el grupo que predominaba era el de los mexicanos, al conformar $63 \%$ del total de la comunidad hispana (BBC Mundo, 2016).

En el Anuario de Migración y Remesas, México 2017, se muestra que para el año 2010, los principales estados del país con mayor flujo migratorio de México a Estados Unidos fueron Zacatecas, Michoacán, Guanajuato, Nayarit y Guerrero. Siendo California, Texas, Illinois, North Carolina y New York los estados con mayor índice de residencia en los Estados Unidos (Serrano, 2017).

Por otro lado, cabe señalar que México es un país en el cual ocurre tanto la inmigración como la emigración, así como también es un territorio transitorio, existe migración de retorno, al igual que los desplazamientos internos, es decir, es un país complejo en cuanto a su movilidad humana (Instituto de Estudios y Divulgación Sobre Migración, A. C. [INEDIM], 2017). Dicha movilidad que se da en el país, en su mayoría se hace de manera clandestina, lo cual se vuelve un peligro para las personas que transitan por el país; día con día se convierten en víctimas de robos, violaciones, extorciones y secuestro a causa de la inseguridad y desprotección a la que se enfrenta este vulnerable grupo social (Carrasco, 2013).

Como ya se mencionó anteriormente, Zacatecas es uno de los estados de la República con mayor flujo migratorio. Durante décadas, la migración de Zacatecas a Estados Unidos aumentó continuamente, cifras que se detuvieron para el año 2005; de haberse registrado, 350,276 personas para el periodo de 1990-2000 pasaron a ser hasta 576,441 personas, cifra que disminuyó para el lapso de 2005-2010, tan solo se presentó un flujo de 31,817 (Padilla, \& Torres, 2012). Asimismo, se deben mencionar cuáles han sido los principales municipios del estado con mayor índice migratorio, en primer lugar se encuentra Susticacán, seguido de General Francisco Munguía, después Apozo, Apulco y Nochistlán de Mejía; del mismo modo, son Texas, California, Illinois, Colorado y Oklahoma las localidades de Estados Unidos en las que principalmente se establecen para residir los zacatecanos (Serrano, 2017). 
$\mathrm{Si}$ bien, se sabe que Zacatecas desde su descubrimiento se ha caracterizado por su alta producción en minerales, lo que en tiempos de la conquista lo hizo posicionarse en uno de los centros económicos más importantes para la Nueva España (Servicio Geológico Mexicano, 2017). Siendo éste un factor importante como causa de la migración, ya que por mucho tiempo la minería fue una de las principales fuentes de empleo para los habitantes del Estado, sin embargo, con la llegada de industrias extranjeras y el uso de maquinarias, comenzaron a disminuir los empleos, lo que orilló, en muchos casos, a la población a migrar (Moctezuma, 2013).

Por último, cabe destacar que, lamentablemente, Zacatecas al igual que todo el país se ha enfrentado a una fuerte transición demográfica, razón por la cual existen comunidades que ya no se encuentran pobladas, y pocas son las que tiene población joven, así como también ha comenzado a verse un déficit en la población masculina, resultado de los desplazamientos humanos (Moctezuma, 2013).

\section{Migración y cultura: Multiculturalidad e interculturalidad}

Allá nosotros los mexicanos, al menos así yo le veo, ahora si como dice la India María 'ni de allá, ni de aqui' no, no, esto es nuestro México, esta es nuestra cultura, nuestra lengua, nuestro idioma, nuestras costumbres, nuestra gente (Roberto, 40 años)

Gonzales (1987) define la cultura como un modo de orden en la vida, por medio de la cual podemos estructurar nuestro presente y futuro, ya que se vuelve la raíz de lo que hemos sido a lo largo de nuestra vida, es decir, la cultura se convierte en la memoria de nuestros días. Trujillo (2005) menciona que la cultura es un elemento esencial para una sociedad, pues le da una estructura y sentido al mundo social. Por otro lado, la cultura se relaciona con la religión, el arte y las costumbres, así como también con el orden político de una sociedad (Molano, 2007). La cultura es holística, todo aquello que esté en contacto con las personas y esté hecho por ellas da origen a una cultura, o bien, se conforma tanto por lo material como por lo espiritual, pues una manifestación humana es un producto cultural (Romero, 2005).

A la naturaleza cultural y diversidad cultural, o sea, las diferentes etnias, lenguas o religiones que existen en una sociedad humana, se le ha apropiado el término multicultural (Organización de las Naciones Unidas para la Educación, la Ciencia y Cultura [UNESCO], 2006). Díaz (2009) dice que el multiculturalismo puede ser lo mismo que la diversidad cultural, ya que se refiere a la existencia de varias culturas en un mismo territorio. Por otro lado, Hernández (2007) menciona que la multiculturalidad es la existencia y convivencia entre diferentes culturas situadas en el mismo lugar, y el multiculturalismo va en dirección a lo normativo, ya que a través de éste se espera una regulación en la convivencia entre culturas.

Al proceso que surge de un intercambio de diálogo o interacciones entre grupos culturales 
diferentes, se le llama interculturalidad; ésta busca una convivencia pacífica entre las sociedades multiculturales (UNESCO, 2006). Como lo menciona Walsh (2005), la interculturalidad no se refiere solamente al contacto entre culturas, el término está más enfocado a la igualdad entre diversas culturas y a la "comunicación y aprendizaje entre personas, grupos, conocimientos, valores y tradiciones distintas, orientada a generar, construir y propiciar un respeto mutuo, y a un desarrollo pleno de las capacidades de los individuos, por encima de sus diferencias culturales y sociales" (p. 4).

La llegada de inmigrantes a otros países no es la razón por la cual se han convertido en multiculturales, pues las sociedades presentes en cada país ya son multiculturales internamente, debido a las diferentes lenguas, religiones o etnias que existen (Serafi y Gimeno, 2006). Gómez (2013) menciona la importancia del reconocimiento de culturas que se comparten en un territorio, logrando acceso a oportunidades, ya sean económicas, políticas, sociales y de comprensión para obtener una igualdad entre ellas.

Cuando se hace un reconocimiento de la cultura del migrante, comienza una transferencia intercultural que, según Mateos (2010), es cuando personas e ideas transcurren entre dos culturas y sociedades diferentes. De esta manera, la persona multicultural, es decir, quien esté interactuando con el migrante de cultura opuesta, logrará comenzar a entablar una correcta comunicación intercultural (Nicolás, 2010).
Casasa (2008) menciona que:

La migración trae consigo la ampliación del radio de las relaciones sociales y la conformación de nuevos vínculos laborales, amistosos o amorosos. Del mismo modo, las diversas expresiones culturales cobran mayor relevancia tanto para la integración y conservación de la cultura original como para la construcción del imaginario colectivo de una nueva identidad (p. 35).

Por esto mismo, los migrantes trabajan arduamente para lograr un equilibrio entre sus familias, el hogar y el entorno social al que se enfrentan en los Estados Unidos, por ello, muy pocos migrantes viajan solos, siempre tienen un amigo o pariente que los acompaña y con quien cumplirán su destino (Cohen, 2004). Con frecuencia, las familias de los migrantes los siguen después, aunque no siempre es así (Cárcamo, 2010). García, Barragán y Granados (1999) señalan que cuando migra la familia nuclear completa, la perspectiva intercultural toma importancia en la educación de los hijos, pues en los países de la cultura dominante se habla más sobre una educación multicultural y no intercultural. Para los niños migrantes, la escuela constituye una forma de inserción, inclusión y ascenso social entre la población nueva (Martínez, Diez, \& Novaro, 2015).

En resumen, se pierde el proceso de interculturalidad al momento en el que excluimos a un migrante; la discriminación a los migrantes 
contribuye meramente a la creación de violencia, más no a una cultura universal (Serafi y Gimeno, 2006). Un país se volverá intercultural y se reflejará el pluralismo cultural en el momento que acepte a los migrantes y a sus familias, sin importar sus grupos étnicos, permitiéndoles así guardar las características culturales que los definen en su grupo social (Casasa, 2008). Como lo mencionan Serafi y Gimeno (2006), la falta de gestión hacia la interculturalidad es una manera de ocultar la verdadera amplitud de nuestros problemas de igualdad, económicos, políticos y culturales. El interculturalismo es una propuesta normativa, que no se debe confundir ni con la diversidad cultural ni con el multiculturalismo.

\section{Identidad y adaptación cultural del migrante}

La identidad del migrante es un tema muy poco estudiado desde el punto de vista de ellos; esta se ha convertido en un fenómeno poco visible, no obstante, se construye mediante el pensamiento de los migrantes, quienes luchan día con día por darle un sentido a las circunstancias en las que viven (Massey, \& Sánchez, 2007). Se debe explicar de manera muy general qué es la identidad cultural del migrante. La identidad se refiere al sentido de pertenencia en un grupo social específico; las manifestaciones culturales expresan con mayor intensidad la diferencia de identidad entre una sociedad y otra (Molano, 2007). Los mismos grupos sociales establecen y configuran los valores y elementos que desean valorar y asumir como propios, de esta manera se convierten en referentes de su identidad (Tamayo, 2008).
Por esta razón, la identidad se encuentra ligada a la historia y al patrimonio cultural, pues guarda el pasado a través de elementos simbólicos o referentes que ayudan a construir el futuro (Molano, 2007). Golubovié (2011) clasifica la identidad cultural en dos: en la identidad nacional y la identidad cultural, la primera se refiere a un proceso sociocultural, y la segunda pertenece y representa la identidad étnica de un estado.

En muchas ocasiones, los migrantes intentan integrarse de lleno a la cultura dominante, pero conservando su propia identidad de origen (Casasa, 2008). Muchas veces, el migrante de tipo externo, busca a personas que pertenezcan a su ciudad de origen para lograr mantener su identidad cultural, al crear una comunidad trasnacional (Sassone, 2007) y así, identificarse y diferenciarse en su nuevo entorno cultural (Vázquez, 2009), donde comenzarán a realizar nuevas actividades, que van desde la manera en la que trabajan, hasta en la forma de divertirse, para sobrellevar la experiencia de la migración (Vázquez, 2009). En consecuencia, los migrantes buscan mezclar talentos de lo que han aprendido en su país de origen, con los recursos que llegan a encontrar en el lugar de destino para beneficiarse a sí mismos y a sus familias (Cárcamo, 2010).

Cabe señalar que para un migrante es complicado adaptarse a un nuevo contexto cultural, como lo mencionan Zlobina, Nekane y Páez (2004), existen tres aspectos a los que una persona que abandona su cultura se debe adaptar: 
la asimilación psicológica, el aprendizaje de nuevos conocimientos y habilidades sociales y los nuevos comportamientos, acordes con las nuevas tareas que practican. Otro aspecto importante y complicado en la adaptación a la nueva sociedad es el lenguaje y la comida, pues son costumbres que tienen un fuerte carácter simbólico para la persona (Labrador, 2001).

Es importante destacar lo que es la aculturación, denominación utilizada para explicar la adaptación tanto psicológica como sociocultural del migrante en el nuevo contexto social donde se encuentra, ya que es parte fundamental del proceso de adaptación (Ojeda, \& Espinosa, 2007). La aculturación se conforma por cuatro elementos: la integración hace referencia al momento en que una persona se relaciona con individuos de otra cultura, pero sin perder su propia identidad cultural; la asimilación, cuando se tiene el contacto con la otra cultura y se pierde la identidad cultural de origen; la separación, cuando no se toma la cultura del nuevo lugar, pero se conserva solamente la propia; y la marginación, donde no se desea pertenecer a ninguna cultura (Martínez, Peterna, López, \& Martínez, 2007). Dentro del mismo proceso de aculturación, Fajardo, Patiño y Patiño (2008) mencionan que existen dos modelos para la misma, uno se centra en sentimientos, actitudes y conductas, y el otro va dirigido a comprender la manera en que las personas se adaptan a una nueva cultura.

Sucede lo mismo cuando los migrantes se encuentran con sus familias en otro país, aunque puede ser más complicado adaptarse al día a día, a los valores, las creencias, las actitudes, las tradiciones y costumbres que van a compartir entre la nueva sociedad, es entonces el momento de enfrentar un choque cultural (Ojeda, \& Espinosa, 2007). Muchos migrantes consideran su identidad cultural y sus costumbres como algo muy valioso, por lo tanto, buscan mantenerlas en la sociedad a la que se van a integrar (Navas, García, Rojas, Pumares, \& Cuadrado, 2006).

En resumen, todos los migrantes viven y trabajan en un país del cual no son originarios, así es como se enfrentan al mismo desafío de adaptarse a una nueva sociedad, corriendo el riesgo de ser rechazados: tal es la característica que los une, por esta razón se vuelven un grupo vulnerable que puede ser explotado y abusado en sus derechos humanos (UNESCO, 2006).

Dicho lo anterior, tras una breve descripción de la problemática que conlleva el proceso de integración cultural en los migrantes, se presenta la investigación que se realizó durante el año 2017 en la estancia de verano que ofrece el Programa Delfín, en Zacatecas, México, que tuvo como objetivo identificar las principales problemáticas de adaptación en los migrantes, para de la misma manera adentrarse un poco más en el tema y pensar en futuras investigaciones, además de seguir respondiendo preguntas acerca de dicho tema, con ayuda no solo de las pesquisas propias, sino también de las ya existentes: migraciones, causas y nuevas identidades (Rivas, 2016); inmigración y salud psicosocial, creando puentes, formando redes (Ruiz, 2012); y Propuesta y Manual de Indicadores de Inter- 
culturalidad e Inclusión de la Población de Distinto Origen Nacional, Huéspedes, Migrantes y sus Familias en la Ciudad de México (Jardón, 2013), por mencionar algunos. Para concluir, se debe mencionar la importancia que tiene realizar estas investigaciones a través de un método cualitativo, pues es un medio que permite dar voz a los actores sociales para que sean ellos mismos quienes expresen sus experiencias, sentimientos y emociones ante un problema con tanto impacto social en la actualidad.

\section{Método}

\section{Objetivo}

El objetivo de este trabajo es identificar las principales problemáticas de adaptación intercultural a las que se enfrenta un migrante, así como también los aprendizajes y experiencias adquiridas en ese mismo entorno social.

\section{Participantes}

Se trabajó con cinco hombres del municipio de Fresnillo, Zacatecas, que fueron migrantes en Estados Unidos y que al momento del estudio se encontraran residiendo en el municipio, sin importar el tiempo que hubiera pasado desde el retorno, ni su edad, ni estado civil, etc., es decir, el requisito fundamental fue haber sido migrante, así como la disposición de compartir su experiencia. No se tomaron mujeres participantes debido a que en la mayoría de los casos son los hombres los que migran y viven la adaptación en la cultura receptora. Se debe mencionar que los participantes fueron seleccionados a través del muestreo no probabilístico: bola de nieve; fueron elegidas solamente cinco personas, ya que fueron las que accedieron, se tenían previstas más, pero lamentablemente no quisieron participar en el estudio.

\section{Instrumento}

Para recolectar la información necesaria, se diseñó un guion de entrevista, en el cual se abordaron temas sobre cómo fue su experiencia al vivir en el otro país, cuáles eran sus costumbres y tradiciones, si las continuó practicando o si adquirió nuevas, qué habilidades desarrolló en Estados Unidos, qué tan complicado fue adaptarse al idioma y qué problemas culturales tuvo al momento de socializar con la nueva cultura. Cabe señalar que todas las entrevistas fueron a profundidad, por la misma razón solo se elaboró el guion ya mencionado con preguntas abiertas.

\section{Procedimiento}

Se contactó a los migrantes a través de compañeros de la Licenciatura en Psicología de la Universidad Autónoma de Zacatecas (UAZ). Las entrevistas se desarrollaron en el lugar que cada participante eligió: tres de ellos decidieron brindar la entrevista en su casa y los otros dos en su trabajo. Las entrevistas fueron grabadas en voz, bajo la autorización de cada participante; duraron alrededor de 30 a 60 minutos. La información fue enriquecida a través de un diario de campo y descripciones de entrevistas. Después de recabar la información, se realizó un análisis de contenido que nos permitió descubrir lo que había detrás y llegar a dimensiones más profundas de cada mensaje (Gomes-Romeu, 2012). 
Cada entrevista transcrita fue codificada, a cada código se le dio una interpretación según lo que se respondía y con base en eso, se elaboraron mapas axiales de cada entrevista que permitieran un mejor manejo de la información obtenida. Al finalizar todo el proceso antes mencionado, se elaboraron descripciones y breves análisis de cada entrevista con el fin de discernir aún más la información y poder responder a las preguntas de investigación.

Por último, es importante señalar los aspectos éticos que se consideraron, como el no dar a conocer los nombres verdaderos de los participantes, edades y tampoco información personal que ellos decidieran no revelar, así como solo grabar la voz si ellos lo permitían o tomar fotografías si aceptaban, así como respetar pensamientos, creencias, ideologías, costumbres y demás, sin enjuiciar nada de la información obtenida y solo usarla como medio para la elaboración del presente estudio, todo esto a través de un consentimiento informado y la libertad de declinar su participación en cualquier momento.

\section{Resultados}

A través de los cinco migrantes entrevistados de Fresnillo, Zacatecas, retornados de los Estados Unidos, se identificaron las principales problemáticas de adaptación intercultural, además de los aprendizajes que adquirieron en dicho país. A continuación una breve descripción con datos generales de los participantes.
Arturo González tiene 36 años, está casado y con tres hijos. Vivió en Estados Unidos por 10 años y hace apenas dos regresó a su lugar de origen, El Salto, en Fresnillo, Zacatecas. Carlos Ochoa tiene 40 años, es un hombre divorciado, no tiene hijos. Hace cinco años que regresó de Estados Unidos a Fresnillo, Zacatecas, duró en el otro país alrededor de ocho años, los cuales vivió por temporadas, pues duraba de seis a diez meses y regresaba a su hogar. Roberto Mendoza, de 60 años, está casado y con tres hijos. Tuvo la misma experiencia que Carlos, sin embargo, él duró aproximadamente 20 años entre ir y venir como migrante, pues mucho tiempo después uno de sus hijos le ayudó a arreglar sus papeles, por lo cual actualmente aún regresa a Estados Unidos, pero ya como turista. Juan, de 55 años, actualmente está casado y tiene tres hijos. Hace 23 años que regresó a Fresnillo de Estados Unidos, después de 18 años que duró viviendo allá.

Entrando en tema, como se ha mencionado anteriormente a o lo largo del texto, la adaptación del migrante a la nueva cultura se convierte en un reto, pues la forma de vivir en los Estados Unidos es muy diferente a las costumbres mexicanas. Martínez y colaboradores (2007) mencionan la fuerte tolerancia que deben tener los inmigrantes al mantener sus costumbres o al tener que renunciar a las mismas, por lo cual la adaptación, inmigración e identidad son procesos muy complejos. Vallejo y Moreno (2014) describen tres modelos para la 
adaptación cultural o, en otro término, la aculturación (Ojeda, \& Espinosa, 2007), el Modelo Unidimensional de Gordon, el Multidimensional de Scott y Scott, además del Bidimensional de Aculturación de Berry, Kim, Power, Young y Bujaki. El primero que se refiere al momento en el que el migrante adopta por completo todos los valores de la sociedad acogida; el segundo está enfocado en la adaptación en diferentes ámbitos como puede ser la familia, trabajo, amigos, etc., desde una perspectiva objetiva y subjetiva; y el Bidimensional, el más influyente en la literatura, se centra en el mantenimiento de la identidad cultural de origen y el deseo de interactuar con la cultura dominante. Por lo tanto, la adaptación cultural lleva a la persona inmigrante a experimentar sentimientos de satisfacción o de aislamiento al momento de relacionarse, ya se positivamente o negativamente con la cultura dominante (Li, France, Rodríguez, 2013).

Los modelos mencionados en el párrafo anterior son de suma importancia para la identificación de las complejidades de la integración a la nueva cultura. Con base en esto, en muchas ocasiones los migrantes se ven impulsados a tener que cambiar sus costumbres o tradiciones debido al rechazo de su cultura en el lugar de procedencia (Casasa, 2008), pues como lo mencionó uno de los migrantes, "como que no es lo mismo a veces porque pos siempre estás enfocado en el trabajo, esa es la verdad, entonces como que no hay mucho tiempo de, pos de estar festejando..." (Sebastián, 38 años).
Del mismo modo, se ven rodeados de nuevas costumbres, valores o actitudes a las que no estaban acostumbrados en su lugar de origen, lo cual les crea un problema al momento de intentar adaptarse y al tratar de aprender nuevas habilidades para poder salir adelante en la nueva ciudad (Zlobina, et al., 2004). Muchos migrantes se apropian de algunas costumbres y valores, los cuales les sirven a lo largo de su etapa migratoria y el resto de su vida, así lo menciona uno de los migrantes entrevistados: "en cuestión de las festividades de allá a mí no me interesan, pero te digo las costumbres, las disciplinas, las cosas positivas, definitivamente todo" (Juan, 55 años).

Al momento de intentar adaptarse, varios de los migrantes no lograron acoplarse a la nueva cultura, ya que mencionaban que tienen costumbres muy diferentes, como por ejemplo la alimentación: "pero allá hay mucho embutido, mucho rápido, $\mathrm{Mc}$ Donalds, Burguer King y todo ese tipo de comidas rápidas no las recomiendo a nadie" (Juan, 55 años); el clima: "a mí no me gustó vivir allá. Y te voy a decir por qué, porque... por el clima, ese era una este factor importante, que nunca me adapté al clima, el frío muy, muy... este... extremo y el calor también" (Sebastián, 38 años); el idioma: "también porque no sabemos el idioma, somos tratados de diferente manera, de veras, horriblemente, bueno... a mí me toco" (Juan, 55 años); y el tener que vivir de manera ilegal, como lo mencionó un migrante: "vivir de ilegal es estar aislado, haga de cuenta, si estuviera en 
esta casa y no sale más que al trabajito y luego se viene otra vez a meterse" (Roberto, 60 años). Todos estos aspectos traen consigo un choque entre culturas, que desencadena en los migrantes problemas psíquicos, los cuales afectan su integridad (Zlobina, et al., 2004).

Por otro lado, se debe resaltar la importancia de la identidad cultural, pues a través de ésta los migrantes expresaron lo mucho que les sirvió saber quiénes eran y de dónde venían (Tamayo, 2008). Uno de ellos mencionó: “aquí tenemos nuestras culturas, México tiene historia y tiene cultura" (Roberto, 40 años). Otro de los migrantes dijo: "pues debe de ser uno mismo y no perder sus raíces, sus tradiciones, lo que... los valores que le inculcan a uno aquí sus padres, no debe uno de perder eso" (Sebastián, 38 años). Mientras los migrantes conservan su identidad cultural, pueden enriquecer el contacto con las demás culturas, lograr un rica convivencia, así como un intercambio de ideas (Vallespir, 1999). Como lo expresan dos de los migrantes entrevistados: "aprendes a conocer otra cultura, otra clase de personas que tienen a lo mejor ideologías muy diferentes a ti” (Sebastián, 38 años). Sin embargo, los migrantes saben que cuando lleguen a los Estados Unidos es probable que se pierda su identidad, debido a que éste es un país multicultural: "allá los mexicanos pues no sabemos ni quiénes somos, si perdemos nuestra identidad ya nos fregamos" (Roberto, 60 años).

Además, los migrantes adquieren aprendizajes durante su estancia en los Estados Uni- dos, los cuales los ayudan a aumentar habilidades que no habían desarrollado en su lugar de origen (Gómez, 2013) y que, por lo tanto, pueden aplicar al momento de volver a su ciudad; ante esto, uno de los migrantes comentó: “me interesé más en aprender más cosas de la cocina, porque sí me gustó, varias cosas que aprendí de allá, a hacer, por ejemplo, sopas, caldos... de hecho hasta la fecha trato de seguirlas aplicando" (Sebastián, 38 años). El mismo migrante habla sobre su aprendizaje del idioma: "aprendí un poquito de inglés nada más que ya se me está olvidando más o menos". Durante su estadía en los Estados Unidos, los migrantes se ven obligados a aprender lo básico del idioma, es una habilidad que en muchos de los casos se pensaba como un imposible, ya que en su lugar de origen nunca lo hubieran aprendido (Gómez, 2013).

Por otro lado, uno de los migrantes expresa su frustración ante el único aprendizaje que adquirió, que fue aprender a ser explotado, a lo que menciona: “aprendimos, yo lo que sí aprendí es a que no somos más que explotados mientras seamos buenos trabajadores, nos están palmeando, dándonos por nuestro lado, pero cuando no servimos pa'nada... váyanse pa'su tierra" (Roberto, 60 años). Otro de los migrantes también habla de los problemas de explotación a los que se enfrentan: "el sueldo de tres dólares por hora, y luego te dan un trato horrible y te querían exprimir absolutamente todo" (Juan, 55 años). 


\section{Discusión}

Ante los resultados expuestos en el apartado anterior, se confirmó que la adaptación intercultural en un nuevo entorno social es un problema para cualquier persona proveniente de una cultura distinta, la cual se puede lograr si se tiene una claridad de la identidad cultural propia y el reconocimiento de culturas que rodean a la persona que viva la situación, en este caso los migrantes. Los aprendizajes son muchos, más no todos los migrantes los toman como positivos para sus vidas; sin embargo, los que sí los son, les sirven para emplearlos en caso de regresar a su lugar de origen.

Ninguna cultura debería de suplir a otra, al contrario, las migraciones tienen que ser un pretexto para integrar otras culturas, no solo deben de verse como un hecho social y económico (Rivas, 2016). Ya que como lo menciona Ruiz (2012), este proceso muchas veces mencionado, afecta a nivel psicológico la integridad de la persona, se manifiesta un gasto emocional cuando se experimenta el duelo migratorio, que es básicamente el sentimiento de nostalgia al encontrarse en un nuevo territorio, donde se quieren lograr los objetivos mentalizados, pero al mismo tiempo existen las imposibilidades culturales, lingüísticas, de comunicación, etc., que imposibilitan lo deseado (Passalacqua et al., 2013).

Visto lo anterior, la recomendación es realizar más estudios sobre el tema, que se centren no solo en la migración, sino en la importancia de una convivencia y adaptación intercultural positiva entre sociedades distintas, viendo a los migrantes como un grupo desprotegido y con mucha necesidad de integración e igualdad, así como también analizando los daños biopsicosociales que trae consigo la no adaptación al nuevo entorno y las repercusiones no solo individuales, sino a nivel poblacional.

\section{Referencias}

Alba, J., \& Besteiro, C., (2001). Efectos económicos de las migraciones internacionales. Filosofía, política y economía en el Laberinto, (7), 27-40. Recuperado de http:// laberinto.uma.es/index.php?option=com_co ntent\&view $=$ article\&id=118: efectos-economicos-de-las-migraciones-internacionales $-\&$ catid $=41:$ lab7 \& Itemid $=54$

Alfonzo, L. (2005). Migración Interna. Fernando de la Mora, Paraguay: Dirección General de Estadística, Encuestas y Censos. Aragonés, A., Salgado, U., \& Ríos, E. (2008). ¿ A quién benefician las remesas?. Economía unam, 5(14), 37-55. Recuperado de: http:// www.scielo.org. $\mathrm{mx} / \mathrm{scielo}$. php?script=sci_ arttext\&pid=S1665-952X2008000200002

Arango, J. (2003). La Explicación Teórica de las Migraciones: Luz y Sombra. Revista Migración y Desarrollo, (1), 1-31. Recuperado de http://www.redalyc.org/articulo. oa? $\mathrm{id}=66000102$

BBC Mundo. (15 de marzo de 2016). Las Verdaderas Cifras de los Hispanos en 
EE.UU. y Cuánto Poder Tienen. Recuperado de http://www.bbc.com/mundo/noticias/2016/03/160304_internacional_elecciones_eeuu_2016_cifras_latinos_1f.

Canales, A. (2012). La migración Mexicana Frente a la Crisis Económica Actual. Crónica de un Retorno Moderado. Revista Interdisciplinaria da Movilidad Humana, 20(39), 117-134. Recuperado de http:// www.scielo.br/scielo.php? pid $=\mathrm{S} 1980$ $85852012000200007 \& \mathrm{script}=\mathrm{sci}_{\text {_ }}$ abstract\&tlng=es

Cárcamo, U. (2010). Migración, Integración e Identidad en América Latina. Manifestaciones de un Proceso de Construcción Híbrida. Revista Cuadernos Judaicos, (27), 1-14. Recuperado de http://web.a.ebscohost. com.wdg.biblio.udg.mx:2048/ehost/pdfviewer/pdfviewer?vid=7\&sid=5f94c018e671-4233-a 7df-1557fd460dbd\%40session mgr4006

Carrasco, G. (2013). La Migración Centroamericana en su Tránsito por México hacia los Estados Unidos. Revista Alegatos, (83), 169194. Recuperado de http://www.corteidh. or.cr/tablas/r32330.pdf

Casasa, P. (2008). Migración e identidad cultural. Revista Trabajo Social, (19), 35-48. Recuperado de http://www.revistas.unam.mx/ index.php/ents/article/view/20184

Centro Internacional de Derechos Humanos de los Migrantes (CIDEHUM). (2011). Migración e interculturalidad. San José,
Costa Rica: Organización Internacional para los Migrantes.

Cohen, J. (2004). The Culture of Migration in Southern Mexico. Texas: University of Texas Press.

Consejo Nacional de Población. (2010). Índices de Intensidad Migratoria México-Estados Unidos 2010. Recuperado de http://www. conapo.gob.mx/swb/CONAPO/Indices_de_ intensidad_migratoria_Mexico-Estados_ Unidos_2010

Díaz, E. (2009). Multiculturalismo y Educación. Revista Cultura y Representaciones Sociales, 4(7), 27-54. Recuperado de http://www. culturayrs.org.mx/revista/num7/DiazC.pdf

Durand, J., \& Arias, P. (2014). Escenarios Locales del Colapso Migratorio. Indicios desde los Altos de Jalisco. Revista Papeles de Población, 20(81), 165-192 Recuperado de http://www.redalyc.org/ pdf/112/11232148007.pdf

Fajardo, M., Patiño, M., \& Patiño, C. (2008). Estudios Actuales Sobre Aculturación y Salud Mental en Inmigrantes: Revisión y Perspectivas. Revista Iberoamericana de Psicología: Ciencia y Tecnología, 1(1), 39-50 Recuperado de http://revistas. iberoamericana.edu.co/index.php/ ripsicologia/article/view/142

Gamze, A., \& Kemal, K. (2006). Los Dilemas de la Inmigración y la Emigración que Enfrenta Turquía Ante las Puertas de la Unión Europea. Revista Migración y Desarrollo, (7), 120- 
169. Recuperado de http://rimd.reduaz.mx/ revista/rev7/6.pdf

García, J., Barragán, C., \& Granados, A. (1999). Inmigración Extranjera, Formación e Interculturalidad. Recuperado de http://webcache.googleusercontent.com/ search?q=cache:http://www.copmadrid. org/webcopm/publicaciones/social/47536. pdf\&gws_rd=cr\&ei=uh9TWfOYCczemAG $3 \mathrm{jrToCw}$

Golubovié, Z. (2011). An Anthropological Conceptualisation of Identity. Revista Synthesis Philosophica, 26(1), 25-43. Recuperado de https://hrcak.srce.hr/index. php? show $=$ clanak\&id_clanak_jezik $=107859$ Gomes, R. (2012). Investigación Social: Teoría, Método y Creatividad. M. Souza, S. Ferreira \& R. Gomes (Eds.). Análisis e Interpretación de Datos de Investigación Cualitativa (pp. 85-114). Buenos Aires, Argentina: Lugar Editorial.

Gómez, A. (2013). La Interculturalidad en las Migraciones: Análisis Cualitativo Sobre Inmigrantes Retornados a la Comunidad Andina. Bogotá, Colombia: Fundación Esperanza.

Gonzáles, F. (1987). Iglesia y Estado desde la convención de Rionegro hasta el Olimpo Radical 1863-1878. Anuario colombiano de Historia Social y de la Cultura, (15), 91-163. Hernández, M. (2007). Sobre los Sentidos de "Multiculturalismo" e "Interculturalismo". Ra Xamhai: Revista de Sociedad, Cultura y Desarrollo Sustentable, 3(2), 429-442.
Recuperado de http://www.journals.unam. mx/index.php/rxm/article/view/6931

Huesca, R., Arellanez, J., Pérez, V., \& Rodríguez, S. (2006). Estudio de la Relación entre Consumo de Drogas y Migración a la Frontera Norte de México y Estados Unidos. Revista Salud Mental. 29(1), 35-43. Recuperado de http://www.redalyc.org/articulo. oa? $\mathrm{id}=58212906$

Ibáñez, D. (2007). Introducción al Estudio de Asía Central. México: Cuadernos de Estudios Regionales.

Instituto de Estudios y Divulgación Sobre Migración, A. C. [INEDIM]. (2017). Estudios de Migración: Estadísticas. Recuperado del sitio de internet de INEDIM: https:/www. estudiosdemigracion.org/2017/04/13/estadisticas-2/

Instituto Nacional de Estadística y Geografía. (2010). Migración: los que se van y los que llegan. Recuperado de http://cuentame.inegi. org. $\mathrm{mx} /$ poblacion/migracion.aspx?tema $=\mathrm{P}$

Jardón, A. (2013). Propuesta de Indicadores de Interculturalidad e Inclusión de la Población de Distinto Origen Nacional, Huéspedes, Migrantes y sus Familiares en la Ciudad de México. Recuperado del sitio de internet de Instituto de Estudios y Divulgación Sobre Migración, A. C.: https:// www.estudiosdemigracion.org/propuesta-ymanual-de-indicadores-de-interculturalidade-inclusion-de-la-poblacion-de-distinto-origen-nacional-huespedes-migrantes-y-susfamiliares-en-la-ciudad-de-mexico/ 
Labrador, J. (2001). Identidad e Inmigración:

Un Estudio Cualitativo con Inmigrantes Peruanos en Madrid. España: Universidad Pontificia Comillas de Madrid.

Li, Y., France, M., \& Rodríguez, M. (2013). Acculturation And Adaptation. En M. France, G. Helt, \& M. Rodríguez (Eds). Diversity, Culture And Counselling: A Canadian Perspective (pp. 139-156). Canadá: Library And Archives Canada Catalouging in Publication.

Mager, E. (2014). Migración Transfronteriza de los Kikapú y sus Efectos de Identidad. Revista Multidisciplina, (18), 148-177. Recuperado de http://www.revistas.unam.mx/index.php/ multidisciplina/article/view/50699/45456

Martín, M. (2005). Migración Cuba-México. Recuperado de http://biblioteca.clacso. edu.ar/Cuba/cemi-uh/20120822093531/ migcums.pdf.

Martínez, L., Diez, M., \& Novaro, G. (2015). Migración e Interculturalidad: Perspectiva de Derechos y Política Educativa. Revista Antropología y Educación, 6(9), 57-62. Recuperado de http://antropologia.institutos. filo.uba.ar/sites/antropologia.institutos.filo. uba.ar/files/bae_n09_e01a09.pdf

Martínez, M., Paterna, C., López, J., \& Martínez, J. (2007). Autoestima colectiva y aculturación en inmigrantes ecuatorianos. Apuntes de Psicología, 25(1), 67-78.

Massey, D., \& Sánchez, M. (2007). El país Transnacional: Migración Mexicana y Cambio Social a través de la Frontera. En M. Ari- za \& A. Portes (Eds.). La percepción de la Identidad Latina y Americana por parte de los Inmigrantes Latinos (pp. 391-422). Ciudad de México: Universidad Autónoma de México.

Mateos, S. (2010). La Migración Transnacional del Discurso Intercultural: Si Incorporación, Aprobación y Resignificación por Actores Educativos en Veracruz, México (Tesis doctoral, Universidad de Granada). Recuperado de http://untref.edu.ar/sitios/wp-content/uploads/sites/6/2015/05/18893235.pdf

Micolta, A. (2005). Teorías y Conceptos Asociados al Estudio de las Migraciones Internacionales. Revista Trabajo Social (7), 59-76. Recuperado de https://revistas.unal.edu.co/ index.php/tsocial/article/view/8476/9120

Moctezuma, M. (2013). La migración Internacional de Zacatecas y su Relación con el Desarrollo y la Biodiversidad. Estudios del Desarrollo. Recuperado de http://www.estudiosdeldesarrollo.mx/busqueda.php

Molano, L. (2007). Identidad Cultural: Un Concepto que Evoluciona. Ópera, (7), 6984. Recuperado de http://www.redalyc.org/ pdf/675/67500705.pdf

Navas, M., García, M., Rojas, A., Pumares, P., Cuadrado, I. (2006). Actitudes de aculturación y prejuicio: la perspectiva de autóctonos e inmigrantes. Revista Psicothema. 18(2), 187193. Recuperado de http://www.redalyc.org/ articulo.oa?id=72718204

Nicolás, M. (2010). Persona multicultural, comunicación intercultural. La propuesta 
de Amin Maalouf. Revista Nueva Época, (14), 199-216. Recuperado de http://www. scielo.org. $\mathrm{mx} / \mathrm{scielo} . \mathrm{ph} \mathrm{p}$ ? $\mathrm{script}=\mathrm{sci}$ arttext\&pid=S0188-252X2010000200008

Ojeda, A., \& Espinosa, D. (2007). Comunicación y Afrontamiento como Estrategias de Adaptación en Migrantes Mexicanos en Estados Unidos. Revista Psicología Iberoamericana, 15(2), 61-67. Recuperado de http:// www.redalyc.org/html/1339/133915933008/

Organización de las Naciones Unidas para la Educación, la Ciencia y Cultura. (UNESCO) (2006). Directrices de la UNESCO sobre la Educación Intercultural. Recuperado de http:/unesdoc.unesco.org/ images/0014/001478/147878s.pdf

Organización Internacional para los Migrantes. (2006). Derecho Internacional sobre Migración: Glosario sobre Migración. Recuperado de http://publications.iom.int/ system/files/pdf/iml_7_sp.pdf

Padilla, J. \& Torres, M. (2012). La Demografía Zacatecana a Comienzos del Siglo XXI. Migración y Desarrollo, 10(19). Recuperado de http://www.scielo.org. $\mathrm{mx} / \mathrm{scielo} . \mathrm{php}$ ? script $=$ sci_arttext\&pid $=\mathrm{S} 1870-75992012000200005$

Padró, J. (2014). Historia del Egipto faraónico. Alianza Editorial.

Passalacqua, A., Castro, F., Menestria, N., Alvarado, L., Piccone, A., Boustoure, A., \& Gherardi, C. (2013). La Migración y sus Consecuencias en Diferentes Franjas Etarias. Revista Anuario de Investigaciones, 10, 387-
393. Recuperado de http://www.redalyc.org/ pdf/3691/369139949079.pdf

Pérez, R. (2007). Los Efectos de la Migración: Aspectos Sociales, de Salud y Éticos. Revista Ethos Gubernamental, (4). 1-35. Recuperado de http://www.piapr.org/index.php?src=docu ments\&srctype $=$ download\&id $=142$

Pérez, S. (2011). Factores que Intervienen en la Migración de Indígenas Totonacos de Veracruz. Ra Ximhai: Revista de Sociedad, Cultura y Desarrollo Sustentable, 7(3). Recuperado de http://revistas.unam.mx/index. $\mathrm{php} / \mathrm{rxm} /$ article/view/30555

Pérez, M. (2012). "Nuevos" Orígenes ya "Nuevos" Destinos de la Migración México-Estados Unidos: el Caso del Centro de Veracruz. Revista Espiral, Estudios sobre Estado y Sociedad, 20(54), 195232. Recuperado de http://www.scielo. org.mx/scielo.php?script=sci_arttext\&pid $=\mathrm{S} 1665-05652012000200007$

Rivas, R. D. (2016). Migraciones, causas y nuevas identidades. kóot, (7), 101-117. Recuperado de: http://biblioteca.utec.edu.sv/ koot/index.php/koot/article/view/91/90

Rodríguez,D., Turra,C.,Oliveira,G.,\&Wajnman, S. (2013). Efectos de la Migración sobre el Crecimiento Poblacional a Largo Plazo de las Provincias Cubanas. Revista Brasileira de Estudios de Populacao, 30(2). Recuperado de http://www.scielo.br/scielo.php?pid=S0102$30982013000200005 \& \mathrm{script}=\mathrm{sci}$ abstract\&tlng=es 
Romero, R. (2005). ¿Cultura y desarrollo? ¿Desarrollo y cultura?: propuestas para un debate abierto. PNUD, UNESCO.

Ruiz, M. C. (2012). Inmigración Y Salud Psicosocial: Creando Puentes, Formando Redes. Barataria. Revista Castellano-Manchega de Ciencias sociales, (13), 253-273. Recuperado de: http://www.redalyc.org/ $\mathrm{html} / 3221 / 322127623016 /$

Sassone, S. (2007). Migración, Territorio e Identidad Cultural: Construcción de "Lugares Bolivianos" en la Ciudad de Buenos Aires. Revista Población de Buenos Aires, 4(6). Recuperado de http://www.redalyc.org/ articulo.oa?id=74040601

Serrano, C. (2017). Anuario de Migración y Remesas, México 2017. México: Consejo Nacional de Población (CONAPO), Fundación BBVA Bancomer y BBVA Research. Recuperado de https:/www.bbva. com/wp-content/uploads/2017/07/1707_ AnuarioMigracionRemesas_2017.pdf

Servicio Geológico Mexicano. (2017).

Panorama Minero del Estado de Zacatecas. Recuperado de http://www.sgm.gob.mx/ pdfs/ZACATECAS.pdf

Tamayo, L. (2008). Identidad Cultural en los Migrantes. Revista Trabajo Social, (19), 183194. Recuperado de http://www.revistas. unam.mx/index.php/ents/article/view/20192 Trujillo,F.(2005). En Torno ala Interculturalidad: Reflexiones sobre Cultura y Comunicación para la Didáctica de la Lengua. Revista Portal
Lunguarum, (4), 23-39. Recuperado de http:// www.ugr.es/ ftsaez/aspectos/reflexiones.pdf Serafi, J., \& Gimeno, C. (Coords.). (2006). Migración e interculturalidad: de lo global a lo local. Valencia, España: Castello de la Plana: Universidad Jaime I.

UNESCO. (2006). Sixty years of science at UNESCO, 1945-2005: Unesco Publishing

Vallejo, M., \& Moreno, P. (2014). Del Culturalismo al Bienestar Psicológico: Propuesta de un Modelo de Satisfacción Vital en el Proceso de Aculturación de Inmigrantes. Boletín de Psicología. (110), 53-67. Recuperado de https:/www.uv.es/ seoane/boletin/previos/N110-4.pdf.

Vallespir, J. (1999). Interculturalidad e Identidad Cultural. Revista Interuniversitaria de Formación del Profesorado, (36), 45-56. Recuperado de http://w.aufop.com/aufop/ uploaded_files/articulos/1247329607.pdf

Vázquez, S. (2009). Identidad Cultural Incide en la Adaptación de Migrantes: CIPES. La Jornada, 12, 2-3 Recuperado de http:// www.lajornadaguerrero.com.mx/2009/02/08/ index.php? section $=$ cultura\&article $=014 \mathrm{n} 1 \mathrm{cul}$

Villarreal, M. (2017). Replanteado del Debate Sobre Migraciones Internacionales y Desarrollo: Nuevas Direcciones y Evidencias. Revista Interdisciplinar da Mobilidade Humana, 51, 181-198, doi: 10.1590/198085852503880005112

Walsh, C. (2005). La Interculturalidad en la Educación. Lima, Perú: Ministerio de Educación. 
Zlobina, A., Nekane, B., \& Páez, D. (2004). Adaptación de los Inmigrantes Extranjeros en España: Superando el Choque Cultural. Migraciones. (15), 43-84. Recuperado de http://revistas.upcomillas.es/index.php/ revistamigraciones/article/view/4259

Zong, J., \& Batalova, J. (17 de marzo de 2017). Inmigrantes Mexicanos en Estados Unidos. Migration Policy Institute. Recuperado de http://www.migrationpolicy.org/article/ mexican-immigrants-united-states.

Recibido: $29 / 01 / 2018$

Revisado: 05/03/2018

Aceptado: 15/06/2018 